\section{Callus induction and pro-embryogenic mass formation in Myrciaria dubia, an important medicinal and nutritional plant}

\author{
Maria da Conceição da Rocha Araújo ${ }^{1}$, Edvan Alves Chagas ${ }^{2 *}$, \\ Wagner Vendrame ${ }^{3}$, Maria Isabel Garcia Ribeiro ${ }^{1}$, Elias Ariel de \\ Moura ${ }^{1}$, Daniel Lucas Lima Taveira ${ }^{1}$, Pollyana Cardoso Chagas ${ }^{1}$ \\ and Maria Luiza Grigio ${ }^{1}$
}

\begin{abstract}
Caçari is a fruit tree that is native to the Amazon region of Brazil. The fruit is considered to have the highest vitamin C content of any edible fruit (13.757 mg $100 \mathrm{~g}^{-1} \mathrm{dry}$ weight). The objective of this study was to evaluate the effects of 2,4-D and 6-BAP alone or in combination on in vitro callus induction and pro-embryogenic mass formation in caçari stem segments in different culture media as a precursor for caçari micropropagation. The experiment consisted of two culture media (MS and WPM) and combinations of four concentrations of 2,4-D $\left(0,1,2\right.$ and $\left.4 \mathrm{mg} \mathrm{L}^{-1}\right)$ and $B A P\left(0,0.25,0.5\right.$ and $\left.1 \mathrm{mg} \mathrm{L}^{-1}\right)$. The results showed that the highest percentage of callus formation (99\%) was obtained in WPM supplemented with $4 \mathrm{mg} \mathrm{L}^{-1}, 2,4-D$ and $1 \mathrm{mg} \mathrm{L}^{-1} B A P$, and this combination resulted in $93 \%$ pro-embryogenic mass formation.
\end{abstract}

Keywords: Camu-camu, somatic embryogenesis, culture medium, growth regulators

\section{INTRODUCTION}

The Amazon contains a wide diversity of species with economic, medicinal and nutritional potential. Among those species, caçari (Myrciaria dubia (Kunth.) (McVaugh)) stands out. It is a native fruit tree that grows spontaneously on the banks of lakes and rivers of the Amazon and is considered to have the highest content of vitamin C of any edible fruit, with variations between 7.355.20 (Chagas et al. 2015) to 13.756 .79 (Ribeiro et al. 2016) mg vitamin C per $100 \mathrm{~g} \mathrm{pulp}^{-1}$ depending on the stage of maturation (Grigio et al. 2021a). In addition to their high vitamin $\mathrm{C}$ concentration, the fruits show high levels of potassium, anthocyanins, flavonoids, carotenoids and phenolic compounds and are considered functional foods (Castro et al. 2018, Grigio et al. 2021b, Grigio et al. 2021c). This fact has attracted the attention of the food, cosmetics and pharmaceutical industries.

This species is usually propagated by seeds. However, M. dubia seeds are highly recalcitrant; this can be a limiting factor for propagation since the seeds cannot be stored for long periods. In addition, genetic variability among $M$. dubia plants may occur. This variability is undesirable in commercial plantations since the objective is to preserve the uniformity of the orchard, maintain the
Crop Breeding and Applied Biotechnology 21(3): e25442131, 2021 Brazilian Society of Plant Breeding. Printed in Brazil http://dx.doi.org/10.1590/198470332021v21n3a40

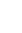


genetic characteristics of the species and especially maximize the genetic gain of new materials that surpass the mean value of the commercial control (Dias et al. 2018). Thus, vegetatively propagate of this species in order to reduce the segregating effect and to reproduce selected high-yielding materials, like the recent study by Lima et al. (2020). However, despite the vegetative propagation technique having a high success rate, it is limited due to the possibility of infestation by pathogens, Therefore, the use of biotechnological techniques with the possibility of preserving the germplasm and producing it on a large scale in a short period of time, such as somatic embryogenesis, is the best alternative (Kamle and Baek 2017, Naaz et al. 2019, Silva-Cardoso et al. 2019).

To initiate the embryogenic process, most species require auxins, usually 2,4- dichlorophenoxyacetic acid (2,4-D) or 1-naphthaleneacetic acid (NAA), either alone or in combination with a cytokinin. For a great number of species, 2,4-D is sufficient to trigger cell differentiation and embryo formation, as it is rapidly metabolized, leading to cell wall thickening and irreversible differentiation in somatic embryos (Corredoira et al. 2019). Some recent studies have shown success with somatic embryogenesis in forest and fruit species of the family Mytarceae: in Acca sellowiana (Pavei et al. 2018, Xiao et al. 2020). Qin et al. (2021) observed the effects of supplementation and the identification of genes and entire genomes of microRNAs. For Psidium guajava (Kamle and Baek 2017) mention that it is necessary to advance in genome sequencing to proceed with studies for Syzygium cumini (L.), and for the first-time advances in somatic embryo aturation were observed in Plinia peruviana (Silveira et al. 2020). However, there is no information in the literature about the callus induction mechanism in M dubia.

In this context, the objective of this study was to evaluate the effects of different concentrations of 6-benzylaminopurine (BAP) combined with different concentrations of 2,4-D in different culture media (MS and WPM) on in vitro callus induction and pro-embryogenic mass formation in stem segments of M. dubia.

\section{MATERIAL AND METHODS}

The experiment was performed at the Tropical Research and Education Center (TREC), University of Florida, located in Homestead, Florida. Stem segments of $M$. dubia plants of approximately $1.0 \mathrm{~cm}$ in length from plants grown for 5 months in a greenhouse at $29^{\circ} \mathrm{C}$ were used as explant sources. The seeds came from the Serra da Prata experimental field of Embrapa Roraima. The stem segments were taken to the ornamental horticulture laboratory and submitted to a precleaning process with $1 \%$ Alconox detergent for 10 minutes. The material was then transferred to a laminar flow chamber for disinfestation using 6\% sodium hypochlorite for 1 minute with 6 drops of Tween 20 followed by three washes with distilled and autoclaved water for $3 \mathrm{~min}$. After disinfestation, the explants were placed in Petri dishes for the different treatments, which consisted of two culture media, MS or WPM, and combinations of different concentrations of 2,4-D (0, 1, 2 and $\left.4 \mathrm{mg} \mathrm{L}^{-1}\right)$ and $\operatorname{BAP}\left(0,0.25,0.5\right.$ and $\left.1.0 \mathrm{mg} \mathrm{L}^{-1}\right)$. In each treatment, $7 \mathrm{~g} \mathrm{~L}^{-1}$ agar, $30 \mathrm{~g} \mathrm{~L}^{-1}$ sucrose, 100 $\mathrm{mg} \mathrm{L}^{-1}$ myo-inositol, and $100 \mathrm{mg} \mathrm{L}^{-1}$ casein hydrolysate were added. The $\mathrm{pH}$ was adjusted to 5.7 using $\mathrm{NaOH}$ before autoclaving at $121^{\circ} \mathrm{C}$ for $30 \mathrm{~min}$.

The experiment used a completely randomized design with a triple factorial scheme consisting of two culture media (MS and WPM), four concentrations of 2.4-D (0, 1, 2 and $\left.4 \mathrm{mg} \mathrm{L}^{-1}\right)$ and four concentrations of BAP $(0,0.25,0.5$ and 1.0 $\left.\mathrm{mg} \mathrm{L}^{-1}\right)$. Each treatment consisted of 5 Petri dishes containing 5 explants each.

After culture establishment, the explants were maintained in the dark in a growth chamber at a temperature of $26 \pm 2$ ${ }^{\circ} \mathrm{C}$ for 60 days for callus formation. At 30 days after culture establishment, the explants were transferred to fresh culture media for continuous callus multiplication. At 60 days after culture establishment, the explants were transferred to fresh culture media without 2,4-D, where they remained for another 30 days in a growth chamber under a $16 \mathrm{~h}$ photoperiod at $28 \pm 2{ }^{\circ} \mathrm{C}$ with a PFD of $52.5 \mathrm{~W} \mathrm{~m}^{-2} \mathrm{~s}^{-1}$. The experiment lasted for a total of 90 days. Subsequently, the percentages of callus and pro-embryogenic mass formation were evaluated. The data were subjected to analysis of variance. The means of the qualitative data were subjected to Tukey's test, and the quantitative data were subjected to polynomial regression ( $p<0.05$ ) using R software (R Core Team 2020).

\section{RESULTS AND DISCUSSION}

The analysis of variance showed a significant effect of the triple interaction among the factors evaluated on callus formation and pro-embryogenic mass formation (Table 1). The analysis of the culture media containing the different 
concentrations of 2,4-D and BAP (Table 1) revealed a higher percentages of callus formation in the WPM culture medium than in the MS culture medium, particularly at higher concentrations of 2,4-D (2 and $\left.4 \mathrm{mg} \mathrm{L}^{-1}\right)$. When 2,4-D was not added to the culture medium, significant differences between culture media were observed only with $0.5 \mathrm{mg} \mathrm{L}^{-1}$ BAP, with $0 \%$ callus formation in the MS culture medium and $60 \%$ callus formation in the WPM culture medium. When using $1 \mathrm{mg} \mathrm{L}^{-1}$ of 2,4-D, no significant differences in callus or mass formation were observed among the treatments. However, the WPM culture medium presented higher means for callus and mass formation compared with those in the MS culture medium.

At a concentration of $2 \mathrm{mg} \mathrm{L}^{-1}$ 2,4-D, significant differences were reported only in the combinations with 0.25 and 0.5 $\mathrm{mg} \mathrm{L}^{-1} \mathrm{BAP}$, resulting in $66.7 \%$ and $66.7 \%$ callus formation in the MS culture medium and $80.0 \%$ and $93.3 \%$ callus formation in the WPM culture medium, respectively. The highest mean values for callus formation were observed for all the treatments at the concentration of $4 \mathrm{mg} \mathrm{L}^{-1} 2,4$ D. When $4 \mathrm{mg} \mathrm{L}^{-1} 2,4-\mathrm{D}$ was combined with 0.25 and $1 \mathrm{mg}$ $\mathrm{L}^{-1} \mathrm{BAP}, 100 \%$ callus formation was reported in the WPM culture medium.

Similar results were observed by Brijwal et al. (2015), who verified that the WPM medium was more effective than other media for leaf explants of Berberis aristata, a medicinal and woody plant, with $97 \%$ callus formation. Conversely, Ahmed et al. (2011), when evaluating the effect of different culture media on callus induction in Phyla nodiflora $\mathrm{L}$. Greene, reported that MS medium combined with $0.6 \mathrm{mg} \mathrm{L}^{-1}$ of 2,4-D produced more embryogenic calli (94.5\%) than WPM medium.

The WPM culture medium was developed for woody crops such as M. dubia and has more diluted nutrient concentrations, mainly of nitrogen and potassium, than other culture media such as MS and JADS. This fact confirms the efficiency of the WPM culture medium for the in vitro propagation of woody species. Sources of $\mathrm{N}$ help to stimulate the proliferation of pro-embryogenic masses and their transformation into different embryonic stages (Carlsson et al. 2017).

Figure 1 shows the percentage of callus formation in M. dubia explants when subjected to different concentrations of BAP and 2,4-D with MS culture medium (Figure 1A) and WPM culture medium (Figure 1B). In the evaluation of the interaction between the BAP and 2,4-D concentrations in the MS culture medium (Figure 1A), an increase in the percentage of callus formation was observed as the concentrations of the growth regulators increased. The best result was obtained at a concentration of $4 \mathrm{mg} \mathrm{L}^{-1} 2,4-\mathrm{D}$ combined with $0.90 \mathrm{mg} \mathrm{L}^{-1} \mathrm{BAP}$, which resulted in $99.9 \%$ callus formation. Conversely, lower percentages of callus formation were observed when no 2,4-D was added to the culture medium. When using only BAP, a small increase in callus formation was observed with the increase in cytokinin concentrations up to $0.73 \mathrm{mg}$ $\mathrm{L}^{-1}$, resulting in $37 \%$ callus formation.

At concentrations of $2 \mathrm{mg} \mathrm{L}^{-1}$ and $1 \mathrm{mg} \mathrm{L}^{-1} 2,4-\mathrm{D}$, an increase in the percentage of callus formation was observed as the BAP concentration increased to 0.9 and $0.64 \mathrm{mg} \mathrm{L}^{-1}$, resulting in means of $95.3 \%$ and $93.07 \%$ callus formation, respectively. Concentrations of BAP higher than $0.64 \mathrm{mg} \mathrm{L}^{-1}$ reduced callus formation. No callus formation was observed when no growth regulators were added to the culture medium. Conversely, higher callus induction percentages were observed for the explants established in the culture media containing the highest concentrations of growth regulators, revealing that they are needed for callus induction in M. dubia explants.

By evaluating the interaction between the concentrations of BAP and 2,4-D with WPM culture medium (Figure 1B), similar behavior to that in the MS culture medium was observed. With increasing concentrations of 2,4-D and BAP, the 
results for callus induction improved. However, the results observed in the WPM culture medium were better than those observed in the MS medium, and the WPM medium generally provided higher callus formation. Higher callus induction was obtained from WPM culture medium combined with $4 \mathrm{mg} \mathrm{L}^{-1} 2,4-\mathrm{D}$ and $0.95 \mathrm{mg} \mathrm{L}^{-1}$ BAP, which resulted in $100 \%$ callus formation. When 2,4-D was not added to the culture medium, lower percentages of callus formation (34\%) were obtained at $0.87 \mathrm{mg} \mathrm{L}^{-1}$ BAP. In treatments without BAP or 2,4-D, the results were much lower than those obtained in the treatments that had cytokinin, demonstrating the need for the interaction of auxin and cytokinin in callus induction for M. dubia explants.

Similarly, Navroski et al. (2012) observed that when using lower concentrations of BAP, callus formation was reduced in stem segments of Satureja hortensis L., and a concentration of $19.45 \mu \mathrm{M}$ resulted in more callus formation. The effects of BAP and 2,4-D on Sorghum bicolor explants indicated that $4 \mathrm{mg} L$ of 2,4-D combined with $1 \mathrm{mg} L$ of BAP were more efficient to callus induction (Espinoza-Sánchez et al. 2018). Similar results for the formation of friable calli were obtained in Berberis aristata which presented greater callus proliferation with the combination of 2,4-D $(4.53 \mu \mathrm{M})$, BAP $(2.22$ $\mu \mathrm{M})$ and NAA $(2.68 \mu \mathrm{M})$, which resulted in $97 \%$ callus formation in leaf explants (Brijwal et al. 2015).

The results reported by Silveira et al. (2020) corroborate the present results. The authors reported no callus induction in leaflets of Plinia peruviana in the absence of 2,4-D. Instead, higher means for callus induction were observed at a concentration with $10 \mu \mathrm{M}$ of 2,4-D, when the explants were maintained in the dark.

A satisfactory percentage of callus and pro-embryogenic mass formation was obtained in the present study. This result is important since it can be used to improve the process of in vitro M. dubia propagation via somatic embryogenesis (SE). In the first stage of the SE is the callus induction, which include the dedifferentiation of cells, activation of cell division and reprogramming of cell physiology, metabolism, and gene expression patterns (Zimmerman 1993). The results revealed the formation of pro-embryogenic masses at the highest concentrations of 2,4-D in combination with BAP. Pro-embryogenic masses were not formed at lower concentrations of these growth regulators (Figure 2).

For the formation of pro-embryogenic mass (PEM), a triple interaction among the tested factors was observed, showing that the culture media and the concentrations of BAP and 2,4-D used in this experiment are directly related to PEM formation. The WPM culture medium presented a higher percentage of PEM formation than the MS medium. PEM formation also presented the best results when high concentrations of BAP and 2,4-D were combined in the WPM medium (Table 2). When 2,4-D was not added to the culture medium, a significant difference was observed only when $0.5 \mathrm{mg} \mathrm{L}^{-1}$ of BAP was used, which resulted in $46.6 \% \mathrm{PEM}$ formation. At the concentration of $1 \mathrm{mg} \mathrm{L}^{-1} 2,4-\mathrm{D}$, no differences were reported between the two media; however, the highest mean values were obtained in the WPM culture medium.

At a concentration of $2 \mathrm{mg} \mathrm{L}^{-1} 2,4-\mathrm{D}$, differences among treatments were observed only with $1 \mathrm{mg} \mathrm{L}^{-1}$ of BAP, which resulted in $60 \%$ PEM formation in the MS culture medium and $86.66 \%$ PEM formation in the WPM culture medium. At the $4 \mathrm{mg} \mathrm{L}^{-1}$ concentration of 2,4-D, when combined with $0.25,0.5$, and $1 \mathrm{mg} \mathrm{L}^{-1} \mathrm{BAP}$, the treatments presented the 

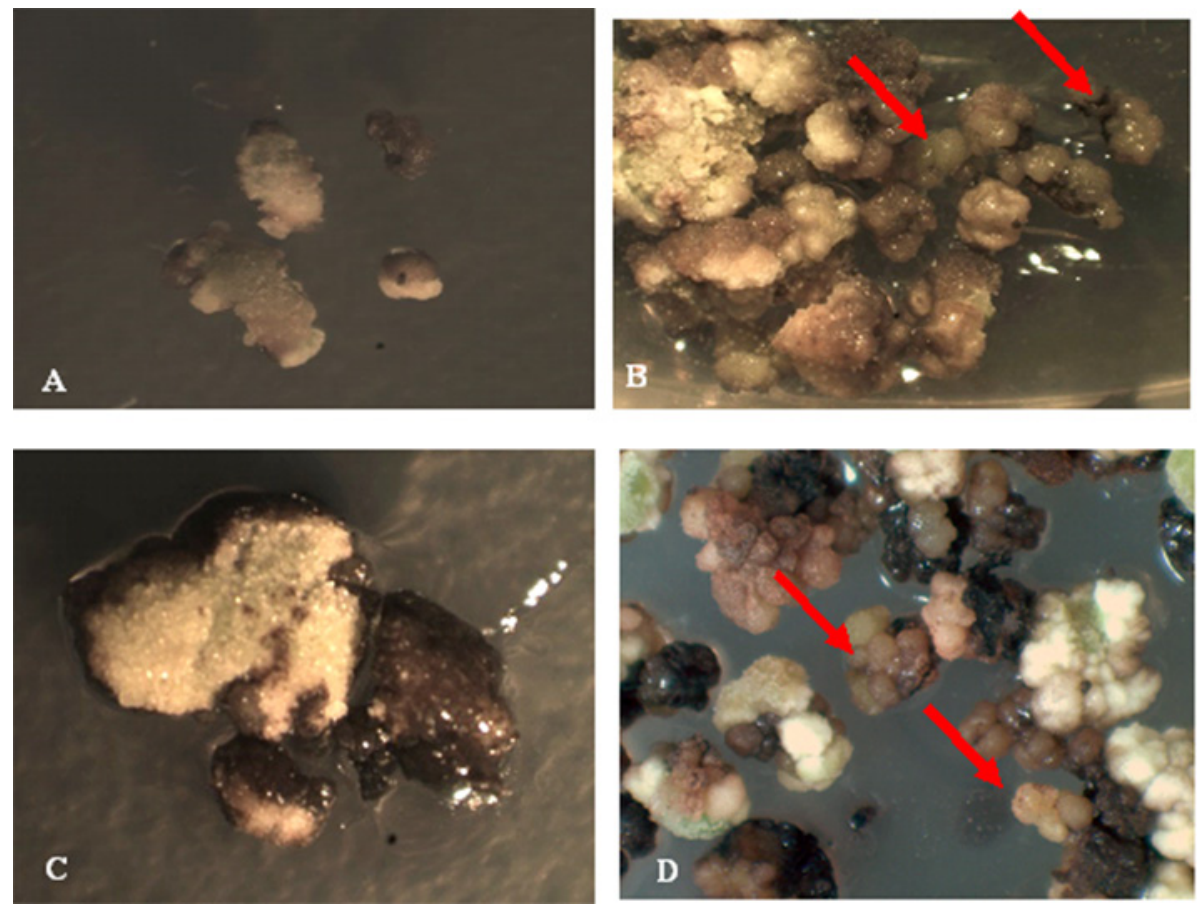

Figure 2. Callus ( $A$ and $C$ ) and pro-embryogenic mass (PEM) formation with globular somatic embryo production (B and $D)$ in $M$. dubia stems at different concentrations of 2,4-D and BAP. (A) $0.25 \mathrm{mg} \mathrm{L}^{-1}$ BAP in MS culture medium, (B) $4 \mathrm{mg} \mathrm{L}^{-1} 2.4 \mathrm{D}^{-1} 1.0 \mathrm{mg} \mathrm{L}^{-1}$ BAP in MS culture medium, (C) $0.25 \mathrm{mg} \mathrm{L}^{-1} \mathrm{BAP}$ in WPM culture medium, and (D) $4 \mathrm{~m} \mathrm{~L}^{-1} 2.4 \mathrm{D}+1 \mathrm{mg} \mathrm{L}^{-1} \mathrm{BAP}$ in WPM culture medium.

highest means, with $100 \%$ PEM formation. The composition of the culture medium is fundamental for the growth and development of in vitro calli. Thus, the WPM medium proved to be the best for the in vitro cultivation of M. dubia since its nutritional composition favors the in vitro cultivation of woody species. The culture medium is essential for the success of somatic embryogenesis (Ramos et al. 2020), and the nutritional balance of macronutrients, micronutrients, vitamins and carbohydrates is essential for morphogenetic transformations in the process of cell dedifferentiation and differentiation (Kulus and Tymoszuk 2020).

M. dubia explants presented excellent PEM formation responses with the addition of 2,4-D and BAP to the WPM culture medium. This finding will make advances in research on the in vitro regeneration of $M$. dubia possible. Figure 3 shows the percentage of PEM formation in $M$. dubia explants subjected to different concentrations of BAP and 2,4-D in the MS culture medium (Figure 3A) and the WPM culture medium (Figure 3B).

When evaluating the interaction between the 2,4-D and BAP concentrations in the MS culture medium (Figure $3 \mathrm{~A}$ ), a linear increase in PEM formation was observed with the increase in the concentration of plant growth regulators.
Table 2. Percentage of pro-embryogenic mass formation in $M$. dubia explants in different culture media at each BAP and 2,4-D concentration

\begin{tabular}{|c|c|c|c|}
\hline \multirow{2}{*}{ 2,4 D $\left(\mathrm{mg} \mathrm{L}^{-1}\right)$} & \multirow{2}{*}{ BAP $\left(\mathrm{mg} \mathrm{L}^{-1}\right)$} & MS & WPM \\
\hline & & \multicolumn{2}{|c|}{ Callus formation (\%) } \\
\hline 0 & 0 & $0 . a$ & $0.0 \mathrm{a}$ \\
\hline 0 & 0.25 & $0.0 \mathrm{a}$ & $16.6 \mathrm{a}$ \\
\hline 0 & 0.5 & $0.0 \mathrm{~b}$ & $46.6 \mathrm{a}$ \\
\hline 0 & 1 & $6.6 \mathrm{a}$ & $6.66 \mathrm{a}$ \\
\hline 1 & 0 & $10.0 \mathrm{a}$ & $23.3 \mathrm{a}$ \\
\hline 1 & 0.25 & 86.6 a & $93.3 \mathrm{a}$ \\
\hline 1 & 0.5 & $66.6 \mathrm{a}$ & $80.0 \mathrm{a}$ \\
\hline 1 & 1 & $53.3 \mathrm{a}$ & $73.3 \mathrm{a}$ \\
\hline 2 & 0 & $20.0 \mathrm{~b}$ & $46.6 \mathrm{a}$ \\
\hline 2 & 0.25 & $26.6 \mathrm{~b}$ & $73.3 \mathrm{a}$ \\
\hline 2 & 0.5 & $60.0 \mathrm{~b}$ & $86.6 \mathrm{a}$ \\
\hline 2 & 1 & 86.6 a & $93.3 \mathrm{a}$ \\
\hline 4 & 0 & $33.3 \mathrm{~b}$ & $66.6 \mathrm{a}$ \\
\hline 4 & 0.25 & $66.0 \mathrm{~b}$ & $100 \mathrm{a}$ \\
\hline 4 & 0.5 & $86.6 \mathrm{a}$ & $100 \mathrm{a}$ \\
\hline 4 & 1 & $93.3 \mathrm{a}$ & $100 \mathrm{a}$ \\
\hline
\end{tabular}

* Means followed by the same letter in the same row do not differ significantly by the Tukey test at the $5 \%$ probability level. 
Better results were observed when using $4 \mathrm{mg} \mathrm{L}^{-1} 2,4-\mathrm{D}$ combined with $0.63 \mathrm{mg} \mathrm{L}^{-1} \mathrm{BAP}$, with a mean of $97.6 \%$ PEM formation. At the concentration of $2 \mathrm{mg} \mathrm{L}^{-1} 2,4-D$, linear growth was observed with the increase in the BAP concentration, resulting in a mean of $86.6 \%$ PEM formation. At concentrations of 0 and $1 \mathrm{mg} \mathrm{L}^{-1} 2,4-D$, an increase in PEM formation occurred when the BAP concentration increased to 0.62 and $0.67 \mathrm{mg} \mathrm{L}^{-1}$, with means of 16.40 and $91 \%$ PEM formation, respectively.

The responses of PEM formation in $M$. dubia explants varied depending on the culture medium and on the concentrations of BAP and 2,4-D used in the experiment (Figure 3B). The WPM medium was more efficient for PEM formation than the MS medium, and better results were obtained when the WPM medium was combined with $4 \mathrm{mg} \mathrm{L}^{-1}$ 2,4-D and $1 \mathrm{mg} \mathrm{L}^{-1} \mathrm{BAP}$, which resulted in $100 \%$ PEM formation. At concentrations of $1 \mathrm{mg} \mathrm{L}^{-1}$ 2,4-D, linear growth was observed with the increasing BAP concentration. When 2,4-D was not added to the culture medium, the PEM formation results were lower; however, a slight increase in the means was observed with an increase in the BAP concentration to up to 0.75 $\mathrm{mg} \mathrm{L}^{-1}$, resulting in $42 \% \mathrm{PEM}$ formation.

The results with low percentages were due to osmotic stress (Kadokura et al. 2018). Similar results were observed by Ratanasanobon and Seaton (2010) when evaluating the effect of different concentrations of 2,4-D on the induction of somatic embryogenesis in leaf explants of Chamelaucium spp. The authors found that higher concentrations ( $5 \mu \mathrm{M})$ of 2,4-D favored tissue differentiation and somatic embryo formation. It is observed in the literature that the use of 2,4 -D individually has greater success (Bajpai et al. 2016, Kamle and Baek 2017). Luis and Scherwinski-Pereira (2014) efficiently induced embryogenic callus formation in Acrocomia aculeate by using low concentration of 2,4-D (1.5 $\left.\mathrm{mg} \mathrm{L}^{-1}\right)$.

Aman and Afrasiab (2014) obtained greater somatic embryo formation (100\%) in Rosmarinus officinalis L. explants, when using $2.25 \mu \mathrm{M}$ of 2,4-D and $2.25 \mu \mathrm{M}$ of BAP in WPM culture medium. The authors observed no embryo formation when only 2,4-D was used, requiring the combination of auxin and cytokinin. Conversely, Sharmin et al. (2014), in a study on Wedeli acalendulacea Less, testing different concentrations of 2,4-D, verified greater conversion of callus into somatic embryos when using low concentrations of 2,4-D $\left(0.5 \mathrm{mg} \mathrm{L}^{-1}\right)$.

\section{CONCLUSION}

This is the first study to show the benefits of 2,4-D for the induction of somatic embryogenesis in Myrciaria dubia. Under the tested conditions for the callus induction of somatic embryogenesis in Myrciaria dubia, the WPM culture medium should be used in combination with $4 \mathrm{mg} \mathrm{L}^{-1} 2,4-\mathrm{D}$ and $0.25 \mathrm{mg}$ or $1 \mathrm{mg} \mathrm{L}^{-1}$ BAP. This research provides significant results for the development of a feasible and efficient in vitro propagation system for Myrciaria dubia. 
Callus induction and pro-embryogenic mass formation in Myrciaria dubia, an important medicinal and nutritional plant

\section{ACKNOWLEDGMENTS}

The authors wish to thank the Coordination for the Improvement of Higher Education Personnel (CAPES) for providing a doctoral scholarship for studies abroad under Strategic Programs, process n: BEX 2724/14-6; the National Council of Scientific and Technological Development (CNPq); and the Foundation for the Environment and Water Resources of the State of Roraima (FEMARH) for financial support. We also thank EMBRAPA and the University of Florida for providing materials, supplies, laboratory and greenhouse space and the opportunity to perform this study.

\section{REFERENCES}

Ahmed ABA, Rao AS, Rao MV and Taha RM (2011) Effect of picloram, additives and plant growth regulators on somatic embryogenesis of Phyla nodiflora L. greene. Brazilian Archives of Biology and Technology 54: 7-13.

Aman N and Afrasiab H (2014) Primary and secondary somatic embryogenesis from leaf explants of ROSEMARY (Rosmarinus officinalis L. - Lamiaceae). Pakistan Journal of Botany 46: 903-909.

Bajpai A, Kalim S, Chandra R and Kamle M (2016) Recurrent somatic embryogenesis and plantlet regeneration in Psidium guajava $\mathrm{L}$. Brazilian Archives of Biology and Technology 59: 1-11.

Brijwal L, Pandey A and Tamta S (2015) In vitro propagation of the endangered species Berberis aristata DC. thourgh leaf-derived callus. In vitro Cellular \& Development Biology Plant 51: 637-647.

Carlsson J, Svennerstam H, Moritz T, Egertsdotter U and Ganeteg U (2017) Nitrogen uptake and assimilation in proliferating embryogenic cultures of Norway spruce-Investigating the specific role of glutamine. PloS One 12: e0181785.

Castro JC, Maddox JD, Cobos M and Imán SA (2018) Myrciaria dubia "camu camu" fruit: health-promoting phytochemicals and functional genomic characteristics. In Soneji J and Nageswara-Rao M (eds) Breeding and health benefits of fruit and nut crops. IntechOpen, London, p. 85-116.

Chagas EA, Lozano RMB, Chagas CP, Bacelar-Lima CG, Garcia MIR, Oliveira JV, Souza OM Morais BS and Araújo MCR (2015) Variabilidade intraespecífica de frutos de camu-camu em populações nativas na Amazônia Setentrional. Crop Breeding and Applied Biotechnology 15: $265-271$.

Corredoira E, Merkle SA, Martínez MT, Toribio M, Canhoto JM, Correia SI, Ballester A and Vieitez AM (2019) Non-zygotic embryogenesis in hardwood species. Critical Reviews in Plant Sciences 38: 29-97.

Dias PC, Xavier A, Resende MDV, Barbosa MHP, Biernaski FA and Estopa RA (2018) Genetic evaluation of Pinus taeda clones from somatic embryogenesis and their genotype $x$ environment interaction. Crop Breeding and Applied Biotechnology 18: 55-64.

Espinoza-Sánchez EA, Sánchez-Peña YA, Torres-Castillo JA, GarcíaZambrano EA, Ramírez JT, Zavala-García F and Sinagawa-García SR (2018) Somatic embryogenesis induction from immature embryos of Sorghum bicolor L. (Moench). Phyton-International Journal of Experimental Botany 87: 105-112.

Grigio ML, Moura EA, Chagas EA, Durigan MFB, Chagas PC, Carvalho GF and Zanchetta JJ (2021a) Bioactive compounds and antioxidant activity of camu-camu fruits harvested at different maturation stages during postharvest storage. Acta Scientiarum. Agronomy 43: e50997.

Grigio ML, Moura EA, Carvalho GF, Zanchetta JJ, Chagas PC, Chagas EA and Durigan MFB (2021b) Nutraceutical potential, qualitative and acceptability of different camu-camu popsicle. Journal of Food Processing and Preservation 45: e15305.

Grigio ML, Moura EA, Carvalho GF, Zanchetta JJ, Chagas PC, Chagas EA and Duringan MFB (2021c) Nutraceutical potential, quality and sensory evaluation of camu-camu pure and mixed jelly. Food Science and Technology 41: fst.03421.

Kadokura S, Sugimoto K, Tarr P, Suzuki T and Matsunaga S (2018) Characterization of somatic embryogenesis initiated from the Arabidopsis shoot apex. Developmental Biology 442: 13-27.

Kamle M and Baek K-H (2017) Somatic embryogenesis in guava (Psidium guajava L.): current status and future perspectives. 3 Biotech 7: 203

Kulus D and Tymoszuk A (2020) Induction of callogenesis, organogenesis, and embryogenesis in non-meristematic explants of bleeding heart and evaluation of chemical diversity of key metabolites from callus. International Journal of Molecular Sciences 21: 5826.

Lima NN, Ferreira SA N and Conceicao JBF (2020) Vegetative rescue of Camu-Camu from epicormic sprouts of detached branches. Revista Brasileira de Fruticultura 42: e- 020 .

Luis ZG and Scherwinski-Pereira JE (2014) An improved protocol for somatic embryogenesis and plant regeneration in macaw palm (Acrocomia aculeata) from mature zygotic embryos. Plant Cell Tissue and Organ Culture1 18: 485-496.

Naaz A, Hussain SA, Naz R, Anis M and Alatar AA (2019) Successful plant regeneration system via de novo organogenesis in Syzygium cumini (L.) skeels: an important medicinal tree. Agroforestry Systems 93: 1285-1295.

Navroski MC, Waldow DAG, Pereira MO and Pereira AO (2012) Calogênese in vitro de segmentos apicais caulinares e internodais em segurelha (Satureja hortensis L.). Agro@mbiente 6: 228-234.

Pavei AF, Fraga HPF, Vieira LN and Guerra MP (2018) Effects of glutathione supplementation and carbon source during somatic embryogenesis of Acca sellowiana (O.Berg) Burret (Myrtaceae). Acta Scientiarum. Biological Sciences 40: e40257.

Qin Z, Li J, Zhang Y, Xiao Y, Zhang X, Zhong L, Liu H and Chen B (2021) Genome-wide identification of microRNAs involved in the somatic embryogenesis of Eucalyptus. G3 Genes, Genomes, Genetics 11: jkab070.

R Core Team (2020) R: A language and environment for statistical 
computing. R Foundation for Statistical Computing, Vienna, Austria. Available at http://www.R-project.org/. Accessed on July 10, 2021.

Ramos JCM, Goelzer A and Damiani CR (2020) Espectro luminoso e bap na indução de plbs a partir de calos de Cattleya nobilior Rchb.f. (Orchidaceae). Revista Brasileira de Engenharia de Biossistemas 14: 402-411.

Ratanasanobon K and Seaton KA (2010) Development of in vitro plant regeneration of Australian native waxflowers (Chamelaucium spp.) via somatic embryogenesis. Plant Cell Tissue Organ Culture 100: 59-64.

Ribeiro PFA, Stringheta PC, Oliveira EB, Mendonça AC and Sant'ana HMP (2016) Teor de vitamina C, $\beta$-caroteno e minerais em camu-camu cultivado em diferentes ambientes. Ciência Rural 46: 567-572.

Sharmin SA, Alam MJ, Sheikh MMI, Sarker KK, Khalekuzzaman M, Haque MA, Alam MF and Alam I (2014) Somatic embryogenesis and plant regeneration in Wedelia calendulacea Less.an endangered medicinal plant. Brazilian Archives of Biology and Technology 57: 394-401.

Silva-Cardoso IMA, Meira FS, Gomes ACMM and Scherwinski-Pereira JE (2019) Anatomical and histochemical studies of the somatic embryogenesis of Syagrus oleracea from immature inflorescences. Crop Breeding and Applied Biotechnology 19: 444-450.

Silveira SS, Sant'Anna-Santos BF, Degenhardt-Goldbach J and Quoirin M (2020) Somatic embryogenesis from mature split seeds of jaboticaba (Plinia peruviana (Poir) Govaerts). Acta Scientiarum. Agronomy 42: e43798.

Xiao Y, Li J, Zhang Y, Zhang X, Liu H, Qin Z and Chen B (2020) Transcriptome analysis identifies genes involved in the somatic embryogenesis of Eucalyptus. BMC Genomics 21: 803.

Zimmerman J (1993) Somatic embryogenesis: a model for early development in higher plants. The Plant Cell 5: 1411. 